\title{
What Should Scientists Do Outside the Laboratory? Lessons on Science Communication from the Japanese Genome Research Project
}

\author{
MACHIKO ITOH \& KAZUTO KATO
}

\begin{abstract}
It is essential for scientists to introduce their research in a comprehensible manner and to communicate with colleagues in the same/different fields and with the public. As genome research requires the massive expenditure of public funds, and raises ethical, legal, and social issues, genome scientists have communicated extensively with the public. In addition, they have established interdisciplinary collaborations that resulted in the creation of a new research field known as bioinformatics.
\end{abstract}

We examined the history of communication activities involving Japanese genome scientists between 1989 and 2005 using extensive literature surveys and interviews. We found that genome researchers went through much trial and error, particularly with respect to collaborative interdisciplinary efforts, and although they early on recognized the necessity of communicating with colleagues in different fields, it was not until the introduction of a large governmental research budget, the Millennium Project $(2000-2004)$, that individual researchers began to be actively engaged in communication activities. In conclusion, to facilitate the participation of scientists in communication activities, researchers who are acquainted with different research fields, community, and society should proactively function as coordinators of interdisciplinary programs or mediators of collaborative research. It is also of primal importance to present to scientists the advantage of dialogue with society scientifically and to design effective communication programs that provide researchers with such opportunities.

\section{Introduction}

In the past, scientists could follow their intellectual curiosity much as artists followed their muse. Pure scientific research had relatively little impact on society and its cost was much less than it is today. This condition has changed drastically. In the life sciences, for example, the sequencing of the human genome has led to new insights ${ }^{1}$, and the expenditures required for research continue to increase. As it is now possible to buy genetically modified foods and to clone one's pet ${ }^{2}$, an average citizen is alert to the possible effects of science on everyday life and monitors the use of research funds more keenly than in the past. Consequently, scientists must disclose their activities and are no longer able to devote their entire effort exclusively to a narrow field of research.

Modern scientific research raises ethical, legal, and social issues (ELSI). Although ELSI has been addressed primarily by sociologists, ethicists, and legal experts, as research budgets mount and the results of research exert a direct impact on society, it has become incumbent on scientists to be mindful of ELSI. This concept is acknowledged in the 'Declaration on Science and the Use of Scientific Knowledge' 
adopted by the 1999 UNESCO-sponsored World Conference on Science. ${ }^{3}$ The declaration confirms that 1) scientific knowledge should be shared, 2) cooperation is needed among governments, civil society, business sectors, and scientists, and 3) scientists must adhere to ethical standards. In the United Kingdom, scientists and government lost public trust over their handling of the outbreak of Bovine Spongiform Encephalopathy (BSE). To restore public faith, the House of Lords Science and Technology Committee recommended a direct dialogue with the public. Their 3rd report influenced the policies promulgated by organizations such as the British Association for the Advancement of Science, and the Royal Institution. ${ }^{4,5}$ An editorial in the journal Nature suggested that the public should be consulted on how government research funds are to be spent. ${ }^{6}$

Thus, scientists are expected to present their research endeavours in a manner comprehensible to the public, ${ }^{7}$ to understand the social implications of their research and its results, and to advance the dialogue with society. ${ }^{8}$ This goal is not easy to achieve. Most researchers do not expect non-researchers to interfere in their research, and do not know effective ways of communicating their research to the public. In fact, this gap itself is an issue to be resolved through dialogue with society. However, is the communication with the public a burden for researchers? For scientists to succeed in their endeavours, they must acquire interdisciplinary knowledge and the ability to publicize their results in a fashion accessible to a wide range of audiences. To develop effective research strategies, they must recognize the relative position of their area of research in a global scientific context as well as the context of societal goals and apprehensions.

Although modern science is highly specialized, seminal work, irrespective of the research area, is related with other fields of science. ${ }^{9}$ It is difficult to keep abreast of detailed developments in multiple fields, but scientists must possess a broad perspective and must understand trends not only in their field but also in a global context of society as a whole to be able to pose fundamental questions and to publish in highly respected journals. The internet provides wide and easy access to research and academic papers (Google scholar: http://scholar.google.com/) and the ISI journal impact factor has been proposed as a quantitative measure of scientific research and its global impact (http://www.isiwebofknowledge.com/). Moreover, the increasingly competitive funding environment makes it necessary for individual scientists to present their research goals clearly. To obtain funding, they must take into account underlying fundamental, and often social, problems and must be able to streamline their research plan and to present their goals and results skillfully.

Here we present the history of the Japanese Genome Research Project (1989 - 2005). We focus on its communication activities including its trial-and-error experience and self-evaluation. Genome scientists have been engaged in wide communications with different research fields and the public, partly because genome science has flourished by cooperating with different research fields, and partly because progress in genome science involves ELSI. This report is a summary of our extensive literature surveys and of interviews with five leading Japanese genome scientists and one ethicist (Figure 1). 


\section{Figure 1}

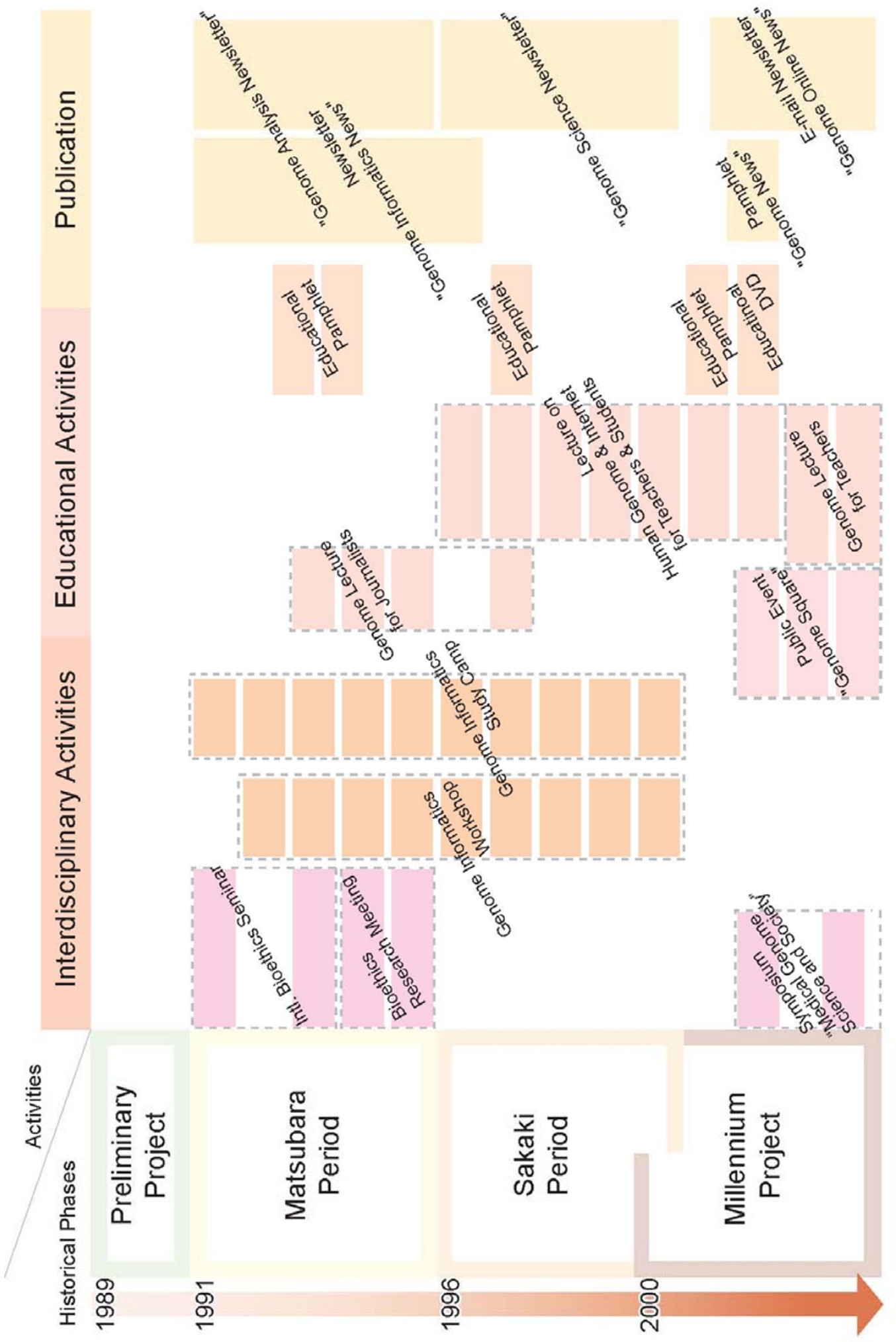




\section{Brief outline of Japanese genome research projects}

Most genome research in Japan has been funded by three ministries, the Ministry of Education, Culture, Sports, Science and Technology (MEXT), the Ministry of Health, Labor and Welfare (MHLW), and the Ministry of Agriculture, Forestry and Fisheries. The latter two primarily support medical and agricultural genomics, respectively, whereas MEXT funds multiple groups to establish interdisciplinary genome sciences.

The Science and Technology Agency (STA), which was merged into MEXT in 2001, took a leading role in the International Consortium for Human Genome Sequencing. It allocated ca. 1 billion yen (or 10 million dollars) per year to the sequencing project from 1995 to 2000 and in 1998 established the Riken Genomic Sciences Center (Riken GSC) in Yokohama as the primary institution for large-scale DNA sequencing and protein structure determination.

Research grants from MEXT are unique in that they encourage academic researchers from different fields to come together to establish interdisciplinary genome sciences. The funded groups include almost all eminent Japanese genome researchers who together as a group led Japanese genome sciences. Currently, approximately 200 laboratories participate in the genome research projects supported by Grants-in-Aid for Scientific Research on Priority Areas from MEXT. Their projects cover medical research, genomics, comparative genomics, and bioinformatics of model organisms. We refer to the genome research projects supported by MEXT as the 'Genome Project' (GP).

Table 1 shows a brief history of the GP. Although there were several independent subprojects conducted in parallel, the effort can be regarded as that of a single community. The GP involved four consecutive periods: the Preliminary Project, the Matsubara Period, the Sakaki Period, and the Millennium Project.

\section{Table 1: Brief History of the GP}

\begin{tabular}{lllll} 
& Fiscal Year & Director & $\begin{array}{l}\text { Number of } \\
\text { Principal } \\
\text { Investigators }\end{array}$ & $\begin{array}{l}\text { Total Amount of } \\
\text { Research Budget } \\
\text { (million yen) }\end{array}$ \\
\hline The Preliminary Project & $1989-1990$ & Kenichi Matsubara & - & 570 \\
\hline The Matsubara Period & $1991-1995$ & $\begin{array}{l}\text { Kenichi Matsubara } \\
\text { Minoru Kanehisa }\end{array}$ & 100 & 2,490 \\
\hline The Sakaki Period & $1996-2000$ & Yoshiyuki Sakaki & 90 & N/A \\
\hline The Millennium Project & $2000-2004$ & Yuji Kohara & 430 & 20,000 \\
\hline
\end{tabular}

\section{The Preliminary Project (1989 - 1990)}

The goal of the Preliminary Project was to formulate genome research in Japan. Members of the Project performed a survey of possible research topics and studied the requirements for driving future genome science in Japan. In its final report, it recommended that the domestic plans for genome research be scheduled as five-year projects to perform full-fledged research. ${ }^{10}$ It also stressed the necessity to form interdisciplinary research groups for the Project, i.e., the research community for bioinformatics and for ELSI. 


\section{The Matsubara Period (1991 - 1995)}

In the subsequent Matsubara Period, basic research started according to recommendations promulgated by members of the Preliminary Project. Two research groups, the biology group and the informatics group, were established and approximately 100 principal investigators were involved (Table 2). ${ }^{11}$ Of these, approximately $10 \%$ participated in both groups.

The biology group constructed genetic maps and cDNA libraries of human (Homo sapiens), worm (Caenorhabditis elegans), and unicellular microorganisms. Experimental techniques such as rapid DNA sequencing and Fluorescent In Situ Hybridization (FISH) were established. The informatics group constructed the widearea network 'GenomeNet' and databases for biological information (http://www.genome.ad.jp/). It also developed tools for genomic data mining. Both groups held annual research conferences and study camps (tutorials) to encourage the participation of computer scientists in genome science.

Table 2: Research Activities in the Three Periods

\begin{tabular}{|c|c|c|c|}
\hline & Director & Research group & $\begin{array}{l}\text { Major research activities and } \\
\text { achievements }\end{array}$ \\
\hline \multirow{2}{*}{$\begin{array}{l}\text { The Matsubara } \\
\text { Period } \\
(1991-1995)\end{array}$} & $\begin{array}{l}\text { Kenichi } \\
\text { Matsubara }\end{array}$ & $\begin{array}{l}\text { Human Genome } \\
\text { Analysis Group }\end{array}$ & $\begin{array}{l}\text { Genetic maps and cDNA libraries of } \\
\text { human, worm, and single-cell } \\
\text { microorganisms, High-throughput } \\
\text { sequencing and FISH techniques }\end{array}$ \\
\hline & $\begin{array}{l}\text { Minoru } \\
\text { Kanehisa }\end{array}$ & $\begin{array}{l}\text { Large-scale } \\
\text { information } \\
\text { Processing Group }\end{array}$ & $\begin{array}{l}\text { Wide-area network 'GenomeNet', } \\
\text { Databases and tools for data mining }\end{array}$ \\
\hline $\begin{array}{l}\text { The Sakaki } \\
\text { Period } \\
(1996-2000)\end{array}$ & $\begin{array}{l}\text { Yoshiyuki } \\
\text { Sakaki }\end{array}$ & Genome Science & $\begin{array}{l}\text { Precise map of human chromosomes, } \\
\text { Functional analysis, Techniques for gene } \\
\text { expression profiling, Databases and tools } \\
\text { for data mining }\end{array}$ \\
\hline \multirow{4}{*}{$\begin{array}{l}\text { The Millennium } \\
\text { Project } \\
(2000-2004)\end{array}$} & Yuji Kohara & Genome Science & $\begin{array}{l}\text { Genome-wide functional analysis, } \\
\text { Comparative genomic analysis, } \\
\text { Sociological research }\end{array}$ \\
\hline & $\begin{array}{l}\text { Sumio } \\
\text { Sugano }\end{array}$ & $\begin{array}{l}\text { Medical Genome } \\
\text { Science }\end{array}$ & $\begin{array}{l}\text { Identification of genes responsible for } \\
\text { lifestyle diseases, Research on } \\
\text { personalized medication }\end{array}$ \\
\hline & $\begin{array}{l}\text { Naotake } \\
\text { Ogasawara }\end{array}$ & Genome Biology & $\begin{array}{l}\text { Experimental analysis of unicellular } \\
\text { organisms and their genetic networks }\end{array}$ \\
\hline & $\begin{array}{l}\text { Toshihisa } \\
\text { Takagi }\end{array}$ & $\begin{array}{l}\text { Genome Information } \\
\text { Science }\end{array}$ & $\begin{array}{l}\text { Analysis of protein structures and their } \\
\text { dynamics, Metabolic and signaling } \\
\text { networks, Simulations }\end{array}$ \\
\hline
\end{tabular}

\section{The Sakaki Period (1996 - 2000)}

During this period, the human genome was sequenced and the complete genomic sequence of several species was released. ${ }^{12}$ Three research subgroups were formed, ${ }^{13}$ the Group for Structure Analysis of the Human Genome prepared a precise genetic map of the human chromosomes and identified some disease-related genes. The Group for Genome Functional Analysis conducted functional analysis of important genes in model organisms and developed experimental techniques for gene expression 
profiling. The Group for Genome Informatics developed algorithms and software programs for data-mining and constructed and maintained databases.

\section{The Millennium Project (2000 - 2004)}

During this post-sequencing era, four research groups were formed, the Genome Science-, Medical Genome Science-, Genome Biology-, and Genome Information Science Group. ${ }^{14}$

The Genome Science Group conducted genome-wide functional and comparative genomic analysis, targeting not only model organisms but also different species. It also included sociological themes such as 'intellectual property' for the first time in GP history. The Medical Genome Science Group employed genotyping to identify genes responsible for diseases and conducted research on personalized medication. The Genome Biology Group was responsible for the experimental analysis of unicellular organisms and their genetic networks. The Genome Information Science Group conducted research on protein structures and their dynamics, metabolic and signaling networks, and simulations.

\section{Results}

In this section we focus on the efforts undertaken to establish new, interdisciplinary areas and to address ELSI in each period (Table 3). We performed extensive literature searches and conducted interviews totaling more than fifteen hours with five leading Japanese genome scientists (Shigeki Mitaku, Asao Fujiyama, Yoshiyuki Sakaki, Sumio Sugano, and Toshihisa Takagi) and one ethicist (Darryl Macer). 
Table 3: Communication Activities in the Three Periods
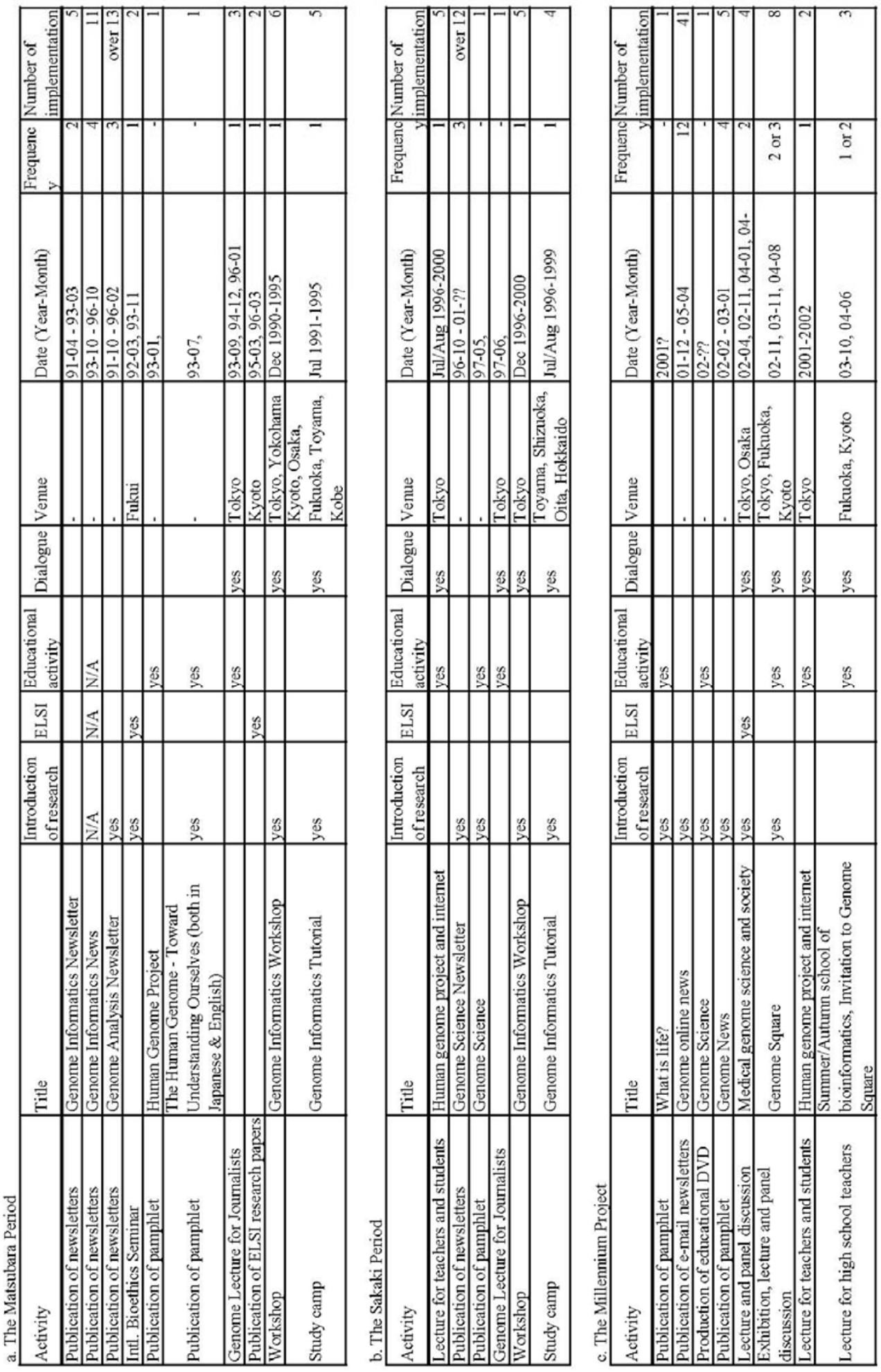

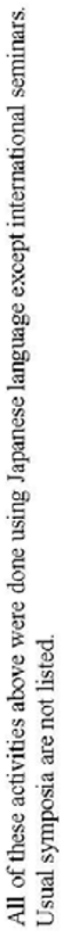




\section{The Preliminary Project (1989 - 1990)}

In their final report, members of the Preliminary Project recommended that future genome research projects should include the participation of computer scientists and that a research community of ELSI should be organized to stimulate discussion [10]. The report also advised that the GP should contain five groups; of these, three were to be involved with experimental biology and two were to be responsible for bioinformatics and ELSI research. Thus, the Preliminary Project membership recognized the importance of science communication and ELSI research to render GP truly interdisciplinary. However, this forward-looking perspective was not fully realized as we describe below.

\section{The Matsubara Period (1991 - 1995)}

In response to the recommendations of the Preliminary Project, participants in the Matsubara Period organized annual Genome Informatics Workshops and Genome Informatics Tutorials (study camps). On average, there were 290 participants in the Workshops and 120 in the Tutorials. Other events were also organized such as the publication of newsletters and lectures for journalists. In addition, seminars on international bioethics were held twice during that period.

One percent of the budget was spent for ELSI research, basically 5 million yen per year. The ELSI research community was led sequentially by three researchers in bioethics. Although no records are available regarding the activities of the first leader, he was succeeded in March 1991 by Norio Fujiki who participated in the Organizing Committee of the second and third International Bioethics Seminar in Fukui Prefecture. In the second seminar, 10 out of a total of 30 speakers were GP scientists. According to the Proceedings of the second International Bioethics Seminar, ${ }^{15}$ most speakers from the GP left immediately after giving their talks and did not participate in subsequent ELSI discussions. Darryl Macer, an ethicist, also reported that many scientists could not well communicate with the audience, and their 'highly technical talks' went over the heads of the audience. ${ }^{16}$ The cooperation between the GP, Fujiki, and the International Seminar ended in 1993, although the Seminar itself was continued thereafter with other scientists in genome sciences who worked on the development of the Universal Declaration on the Human Genome and Human Rights (1995-1997).

The third leader was a philosopher, Hisatake Kato, who joined the GP in $1994 . \mathrm{He}$ organized meetings on bioethics and philosophy, and published two meeting reports; ${ }^{17}$ 26 and 45 contributors submitted papers to the first and second report, respectively. Only one contributor, Keiko Nakamura, was a member of the GP, all others were philosophers or ethicists. Although Nakamura assessed and advised the genome research community in Japan, she was not directly involved in genome research. We can conclude, therefore, that no genome scientists participated directly in this research on ethical issues, and their activities were less effective compared with those by Fujiki, the previous leader.

After this slow beginning, in their proposal to the next GP, genome scientists recommended that ELSI be handled by an advisory board of the GP rather than invited researchers. ${ }^{18}$ In other words, they did not pursue cooperative endeavors with 
philosophers or ethicists to establish a new, interdisciplinary research community.

Newsletters published throughout the period were distributed to GP members and subscribers. One researcher from each group served as editor of the newsletters which included the opinions and impressions of GP members of academic meetings outside the GP. The newsletters also provided space for communication among GP members. In the next period, one editor, Asao Fujiyama, continued to publish the newsletters; the main role of the other editor, Shigeki Mitaku, was in educational outreach activities. They also published pamphlets introducing GP research activities to the wider public.

\section{The Sakaki Period (1996 - 2000)}

This period overlapped with the international competitive human genome sequencing project, and the amount of sequences to be analyzed was drastically increased (http://www.ncbi.nlm.nih.gov/Genbank/genbankstats.html). Scientists were under pressure to speed up their work, and except for educational outreach, ELSI activities and efforts to continue with the establishment of interdisciplinary science faltered during this period; communication activities were continued by a few, highly motivated individuals. The significance of this lack of organization in the GP will be discussed in the next section.

The annual Genome Informatics Tutorials were discontinued at the end of this period. It was thought that the Tutorials had fulfilled their mission, the induction of computer scientists into the GP, based on the observation that the number of newly participating computer scientists had decreased compared to the previous period. Later, however, a similar activity was resumed as a summer school project offered by the Japanese Society for Bioinformatics, a research community that included major members of the GP.

\section{The Millennium Project (2000 - 2004)}

With fiscal year 2000, significant research funding under the designation The Millennium Project was launched. ${ }^{19}$ A large goal of this project was to address lifestyle-related diseases. The funds for life science from MEXT amounted to approximately 10 billion yen per year; 5 billion were allotted to cancer research, 4 billion to genome science, and 1 billion to brain science. ${ }^{20}$ The fund for genome science was increased prominently, reflecting the completion of the Human Genome Project. The number of new GP members grew more than four-fold compared to the preceding Sakaki Period, and approximately $87 \%$ of the members were newcomers. The attitude toward ELSI research began to change due to rapidly increasing research funding for medical applications of genomics. The directors of the four research groups in the GP were conscious of their accountability and they joined the Committee on ELSI and on Public Relations, which until then contained only a few GP participants. The new committee organized the Task Force on Ethical Issues in Medical Genome Research and invited Kazuto Kato, whose background was developmental biology, to join the committee. Kato, who had been engaged in science outreach activities such as the interpretation of current biological research for the public, organized the 'Genome Square' events we describe below. 
In cooperation with eight academic societies including The Japan Society of Human Genetics, the Task Force on Ethical Issues in Medical Genome Research formulated guidelines for genetic testing. ${ }^{21}$ GP members were provided with information regarding prescribed procedures applicable to medical genome research, for example, a procedure for the protection of personal genetic information.

In the course of 2002 - 2004, two-day Genome Square events (http://hiroba.genome.ad.jp/; in Japanese only) were held eight times in three cities (Tokyo, Kyoto, Fukuoka). ${ }^{22}$ The participants from the GP and visitors numbered approximately 1300 and 9700 , respectively. This was the first activity that elicited the participation of a large number of GP members. The event featured exhibitions from approximately 30 GP laboratories, seminars, and panel discussions. Staff members and graduate students from each laboratory were presenters at the exhibitions. The Genome Square events provided researchers with the opportunity to communicate with lay persons from different generations and with different perspectives. Among participants who replied a questionnaire ( $80 \%$ of total), about half answered "yes" to the question "I have reexamined the purpose and meaning of my research through discussions with non-researchers" and "The members of my laboratory were educated and motivated by their participation in this event". 22

Starting with this period, the office work and public relations component of the GP was handed over to a commercial enterprise which published a monthly e-mail newsletter as well as the pamphlet 'Genome News'. The pamphlet was later discontinued and the e-mail newsletter was reduced to short announcements and a listing of the latest publications.

\section{Discussion}

\subsection{Establishment of an interdisciplinary research community}

In this section we review the activities of the GP as it attempted to establish an interdisciplinary research community that included ELSI and bioinformatics components.

\section{The ELSI perspective}

Despite the initial intent to organize an interdisciplinary ELSI research contingent, GP scientists ceased cooperating with philosophers and ethicists at the start of the Sakaki Period. Why did the cooperative efforts fail? According to Sakaki, the ethicists' perspective did not have a sufficiently strong connection with actual genome research. ${ }^{23} \mathrm{He}$ also explained that the focus was shifted from ELSI to the public understanding of genome science as a whole, because ELSI should be treated by MHLW, not MEXT. Fujiyama, on the other hand, contended that bioethics in Japan at that time tended to be impractical because most concepts were directly imported from overseas. ${ }^{24} \mathrm{He}$ also pointed out that the lack of suitable researchers to cooperate on ELSI led to the passive decision, at the start of the Sakaki Period, to assign responsibility for ELSI to a GP advisory board. During the Sakaki Period, 2 senior advisors were assigned responsibility for ELSI, however, no activity records are available. The failure to appoint a coordinator conversant with multiple research cultures and to induct appropriate researchers into the GP, aborted the birth of a truly 
interdisciplinary research community. This situation was also pointed out by Darryl Macer already in 1992: "(Natural) scientists in Japan who do see the relevance of ethical studies do not think they should be the responsibility of natural scientists, but of social scientists or lawyers. But even if social scientists start such research, they may still be unable and/or unwilling to challenge the views of biologists or policymakers". He also remarked in his interview that "I think non-scientists in Japan could engage scientists, but generally do not have the attitude to do so effectively. Often they like to confront scientists. Prof. Fujiki was a medical doctor, and the GP has come back to working with a natural scientist, Dr. Kazuto Kato, to work on social issues and communication. To make the situation better, improve the attitude of all to be multidisciplinary and not threatening each other with a critical attitude". ${ }^{26}$

The GP has now entered the Takagi Period (2005- 2009) in which four principal investigators address ELSI; they are Kazuto Kato and three medical scientists. Their successful collaboration with researchers knowledgeable in the fields of sociology and the humanities may constitute the first step by the GP towards a truly interdisciplinary research.

\section{The bioinformatics perspective}

With the active pursuit of computer scientists by the GP, the scientific community in the Matsubara Period began to establish interdisciplinary bioinformatics research. Indeed, many of the attendees of the Tutorials and Workshops held during the Initial Period now constitute the core of the GP. After the initial influx, however, the number of newcomers from computer science decreased and this was, at least in part, the reason for discontinuing the Tutorials.

According to Toshihisa Takagi, it is difficult for computer scientists to participate in the biological aspects of research because they need to learn the requisite biology background and are still expected to output discoveries in the context of their original area of expertise. ${ }^{27} \mathrm{He}$ estimated that 5 years are required for a computer scientist to publish a first bioinformatics paper; this may explain the reluctance to dive into a new research field. The establishment of more academic departments for bioinformatics could improve this situation, but the creation of new disciplines at Japanese universities is difficult. ${ }^{28}$ For this reason, Takagi confessed, the Bioinformatics Group in the Millennium Project could not be evaluated by the traditional measure of its biological achievements. Newcomers from areas outside biology were given preferential treatment in terms of affirmative programs to encourage their participation in the GP.

The heated competition among sequencing centers during the Sakaki Period may constitute another reason for the discontinuation of interdisciplinary GP activities: scientists had little time to cultivate new areas of research, and this attitude was carried over into the Millennium Project. Under these circumstances, the Genome Square events provided a unique opportunity for graduate students to survey a wide range of genome research and to communicate with researchers in different fields. Although the Genome Square events were initially intended to offer researchers and the general public an opportunity for exchanges in a social setting, they also served as an introduction to interdisciplinary education for young scientists. ${ }^{22}$ 
In the Takagi Period, scientists from the field of biology and informatics joined a single group known as "Biological Systems Informatics". According to Takagi, the formation of this group constitutes the end of the affirmative program and, simultaneously, a step toward establishing a truly integrated science.

\subsection{Communication successes and failures of the Millennium Project}

With the almost seven-fold increase in research funding, leading scientists in the Millennium Project became highly conscious of the social implications of their work. A cumulative total of 1300 scientists participated in the Genome Square events and communicated with the public.

Concurrently, GP scientists stepped up their participation in ELSI activities. In the Matsubara Period, the Committee on ELSI and Public Relations consisted of only two advisory researchers and invited ethicists. Only invited researchers conducted ELSI activities and the participation of genome scientists was lacking. In the Sakaki period, the Committee consisted of only two advisory researchers and no ELSI activities were pursued. On the other hand, in the Millennium Project, the Committee is comprised of one advisory scientist, the directors of the four research groups, Kazuto Kato, one legal expert, and one medical researcher who serves as director on ethical issues in medical genome research. The Committee organized the Genome Square events and symposia on social issues in medical genome science ("genome ikagaku to shakai") and more GP members than ever participated in these events.

According to Sumio Sugano, however, the main reason for the shift in the attitude of genome scientists toward social activities was increasing outside pressure for the GP to justify its huge budget requests [20]. While some scientists had long been cognizant of their responsibility toward society as a whole, some participants in the Genome Square events continued to regard their participation in these activities as an unwelcome burden (personal communication). There were additional failures. In the Matsubara and Sakaki Period, educational outreach activities and the publication of newsletters involved a few individual scientists who labored on a volunteer basis. In the Millennium Project, the production of newsletters was placed into the hands of a professional office. Consequently, the newsletters became reminiscent of official reports rather than the more satisfying lively exchange of letters among GP participants. Moreover, the pamphlet 'Genome News' was suddenly discontinued when the office was succeeded by a different company.

\subsection{The attitude toward society}

We have seen that only after the Millennium Project started, many researchers began to participate in the ELSI activity. Before then, how had the communication between the research community and society been recognized by the organizers of the GP? In the Matsubara Period, social activities meant the research on bioethics and the education of journalists. For the Sakaki Period, let us quote the Sakaki's own remark in his interview: "We tried to emphasize educational activities, basically because we were engaged in basic science (and we needed public understanding). So I personally showed up in many TV programs and public lectures. It is my contribution that the public came to be familiar with the word 'genome'." (Parenthesized part is by the 
authors.) In the Sakaki Period, a few highly motivated GP researchers organized and participated in the outreach activities: one lecture course for journalists and five for (junior) high school teachers and pupils. The remark of the principal organizer of the high school lecture courses, Shigeki Mitaku, is noteworthy: "Answering to the questions from the public is rewarding for both researchers and the public, because we always face fundamental, top-down questions in the process. We start to see our research from the viewpoint of the public. The important point is the motivation for the good of the society". ${ }^{29}$ In the Millennium Project, the symposia "Medical genome science and society" and the event "Genome Square" were conducted in addition to educational activities. These activities were intended as a dialogue with the society, in parallel with the international movement as described in Introduction.

\subsection{Conclusions}

Although the establishment of an interdisciplinary research community was recognized as an important issue even in the Preliminary Project, this goal has not been fully realized yet. GP scientists failed to identify appropriate collaborators to address ELSI from ethical perspective and the establishment of the interdisciplinary bioinformatics community encountered similar difficulties. The number of participating computer scientists declined as the GP progressed, presumably because of a lack of academic departments and bioinformatics positions. To facilitate researchers' participation in interdisciplinary programs, therefore, researchers who are acquainted with different research fields, community, and society should proactively function as coordinators of interdisciplinary programs or mediators of collaborative research.

As for the dialogue with society, researchers began to recognize its importance in their research. Indeed, GP researchers' attitude toward society has changed from one-way education to dialogue in the Millennium Project. Many researchers participated in the social events such as Genome Squares and experienced dialogue with society. Therefore, it is of primal importance to present to scientists the advantage of dialogue with society scientifically and to design effective communication programs that provide researchers with such opportunities.

\section{Acknowledgments}

The authors thank five eminent Japanese scientists (Drs. Shigeki Mitaku, Asao Fujiyama, Yoshiyuki Sakaki, Sumio Sugano, and Toshihisa Takagi) and one ethicist (Dr. Darryl Macer) for graciously allowing us to conduct interviews and for providing historical documents, Dr. Masanori Arita for suggestions and comments, and Ursula Petralia for editing the manuscript. This work was supported by a Grant-in-Aid for Scientific Research on Priority Areas "Genome Science" from the Ministry of Education, Culture, Sports, Science and Technology of Japan. 
${ }^{1 .}$ International Human Genome Sequencing Consortium. Finishing the euchromatic sequence of the human genome. Nature 2004; 431(7011): 931-945.

2. Hinman, L. M. 2004. The Ethics of Cloning Pets. In Op-ed Page of Los Angeles Times, August 28. (Available at http://ethics.sandiego.edu/lmh/op-ed/CloningPets/CloningPets.html)

${ }^{3 .}$ UNESCO World Conference on Science. 1999. Declaration on Science and the Use of Scientific Knowledge. (Available at http://www.unesco.org/science/wcs/eng/declaration e.htm)

4. House of Lords Science and Technology Committee. 1999. Science and Technology - Third Report. (Available at http://www.parliament.the-stationeryoffice.co.uk/pa/ld199900/ldselect/ldsctech/38/3801.htm)

${ }^{5}$ Briggs, P. 2001. New visions for associations for the advancement of science : a case study. In Science communication in theory and practice (Stocklmayer, S.M. et al eds.) Springer/Kluwer.

${ }^{6}$ Editorial. Going Public. Nature 2004; 431(7011): 883.

7. U.S. Department of Health and Human Services - Public Health Service. 2004. Grant Application PHS 398. (Available at http://grants.nih.gov/grants/funding/phs398/phs398.html)

${ }^{8 .}$ Leshner, AI. Public Engagement with Science. Science 2003, 299(5609): 977.

9. Garfield, E. The significant scientific literature appears in a small core of journals. The Scientist 1996; 10(17): 13

10. Final Report of the "Preliminary Period" (in Japanese). Available on request from the authors.

11. Final Report of "Analysis of the Human Genome" (in Japanese). Available on request from the authors.

12. Fleischmann RD, Adams MD, White O, Clayton RA, Kirkness EF, et al. Whole-genome random sequencing and assembly of Haemophilus influenzae Rd. Science 1995; 269(5223): 496-512.

13. Final report of "Genome Sciences" (in Japanese). Available on request from the authors.

14. Final report of the "Millennium Project" (in Japanese). Available on request from the authors.

15. Human genome research and society (Fujiki, N., Macer, DRJ. eds.) Proceedings of the 2nd International Bioethics Seminar in Fukui, 20-21 March 1992, Christchurch, NZ. Eubios Ethics Institute (1992)

16. Swinbanks, D. When Silence isn't golden. Nature 1992, 356(6368): 368.

17. Second Research Proceedings of "Interface between human genome research and society", 1996, Department of Ethics, Graduate School of Letters, Kyoto University, (in Japanese).

18. Final report of "Proposal to the Genome Science" (in Japanese). Available on request from the authors.

19. Saegusa, A. Japan banks on budget to boost biotechnology. Nature Biotechnology 2000; 18(2): $142-$ 142 .

20. Interview with Sumio Sugano, conducted at The Human Genome Center, Tokyo, on May 21, 2005 by Machiko Itoh.

21. Guidelines for gene diagnosis and therapy (in Japanese). Available on request from the authors.

22. Final report of "Genome Square" (in Japanese). Available on request from the authors.

${ }^{23}$ Interview conducted at the Riken Genome Sciences Center, Tokyo, on October 8, 2004 by Machiko Itoh.

24. Interview conducted at The National Institute of Informatics, Tokyo, on August 4, 2004 and November 5, 2004 by Machiko Itoh.

25. Macer, D. The 'far east' of biological ethics. Nature 359(6398):770.

26. E-mail interview was conducted in Aug, 2005 by Machiko Itoh and Kazuto Kato.

27. Interview conducted at The University of Tokyo, on June 4, 2005 by Machiko Itoh.

${ }^{28 .}$ Kishi, N. 2004. Genomu Haiboku (in Japanese; English title: A Defeat in the Genome Project).

Diamond Publishing: 374 pp. Reviewed by Ito, Y. Nature 2005; 433: 107-108.

29. Interview conducted at Nagoya University, Nagoya, on July 27, 2004 by Machiko Itoh. 